\title{
Changes in skinfolds during pregnancy
}

\author{
BY NAN R. TAGGART*, RUTH M. HOLLIDAY, \\ W. Z. BILLEWICZ, F. E. HYTTEN AND A. M. THOMSON \\ Reproduction and Growth Research Unit (Medical Research Council), \\ Princess Mary Maternity Hospital, Newcastle upon Tyne $2 \dagger$ \\ (Received I2 October 1966-Accepted 28 November I966)
}

I. Skinfold thicknesses at seven sites were measured during and after pregnancy in eightyfour women; in forty-eight of these, total body water was measured concurrently.

2. Early in pregnancy (10 weeks) the skinfold measurements were highly correlated with each other and with maternal weight, ratio of observed weight to standard weight-for-height, 'dry' (water-free) weight, and with calculated estimates of body fat.

3. At nearly all sites, skinfold thicknesses increased up to about 30 weeks of pregnancy. Increases were greater at 'central' and least at 'peripheral' sites, and were not proportional to the initial skinfold thickness.

4. From 30 to $3^{8}$ weeks of pregnancy, the patterns were variable: the mid-thigh skinfold continued to increase and at the other sites there was little change or a decrease.

5. All sites decreased by a surprisingly large amount between 38 weeks of pregnancy and the end of the first post-partum week. The evidence suggests that this change, which was not related to the presence or absence of oedema, occurred about the time of parturition.

6. From the end of the first post-partum week to 6-8 weeks post partum, the changes were again variable.

7. The increase of skinfolds during pregnancy was greater in underweight than in overweight women, and in primiparae than in multiparae. The pattern of change was not affected in any consistent manner by oedema.

8. The changes in skinfold thicknesses during pregnancy, especially up to about 30 weeks, showed patterns similar to those of total body-weight and 'dry' body-weight. A formula is given by means of which 'dry' weight can be predicted from five skinfolds, height and duration of gestation.

Preliminary studies of gains in body-weight and changes in body composition indicated that the average healthy pregnant woman lays down a considerable amount of body fat, especially around mid-pregnancy (Thomson \& Hytten, I96r; Hytten \& Leitch, 1964). Much of this extra fat seemed likely to be deposited subcutaneously, and this has now been investigated by measuring skinfold thicknesses at intervals during the course of pregnancy.

\section{EXPERIMENTAL}

\section{Subjects}

Skinfolds were measured serially in eighty-four healthy, pregnant women who had been booked for confinement at the Aberdeen Maternity Hospital. They were selected from a larger number, grounds for exclusion being gaps in observation, therapeutic alterations of diet, twin pregnancy, and gestation period under 38 weeks. In forty-eight of the selected subjects, total body water was measured concurrently by the dilution

* Present address: College of Domestic Science, Queens Road, Aberdeen.

+ The work described in this paper was undertaken when the authors were on the staff of the Medical Research Council's Obstetric Medicine Research Unit, Aberdeen. 
method, using deuterium oxide as the tracer (Hytten, Thomson \& Taggart, 1966). All subjects under consideration delivered healthy babies, and in nearly all the course of pregnancy had been quite normal.

\section{Measurements of skinfolds}

Measurements were made by one observer (N.R.T.) with a Harpenden skinfold calliper with faces of $6 \times 15 \mathrm{~mm}$ and exerting a constant pressure of $10 \mathrm{~g} / \mathrm{mm}^{2}$ (Edwards, Hammond, Healy, Tanner \& Whitehouse, 1955). The procedure was carefully standardized, and each measurement was made in triplicate on the left side of the body; the results were averaged.

Some conventional sites are difficult to use during the later part of pregnancy. After preliminary trials, the following sites were adopted for use during the present study:

(I) Triceps Midway between deltoid process and olecranon, over triceps

(2) Biceps Similar, over biceps

(3) Scapula Below tip of left scapula

(4) Costal In the mid-axillary line at the level of the lowest rib

(5) Suprailiac Midway between the anterior superior iliac spine and the lowest point of the ribs

(6) Mid-thigh Front of thigh at mid-point

(7) Knee-cap Suprapatellar.

Most subjects were measured at each antenatal visit, at intervals which decreased from 4 weeks at the beginning of pregnancy to $\mathrm{I}$ or 2 weeks at the end of pregnancy. As far as possible antenatal visits included appointments at $10,20,3^{\circ}$ and 38 weeks of pregnancy, and skinfold thicknesses in these weeks have been used for purposes of analysis.

When measurements were not made in these weeks exactly, they were estimated by interpolation; subjects with large gaps in the serial measurements had been excluded previously. Measurements were repeated postnatally at the time of discharge from hospital about I week after delivery, and again at the postnatal visit, at 6-8 weeks post partum.

No 'correction' has been made for skin thickness, i.e. the skinfold measurements quoted include double layers of skin and of subcutaneous tissue.

In order to determine the reliability of measurements, five non-pregnant women were measured on five occasions within 14 days by N.R.T. The following means, and coefficients of variation between successive measurements on the same subject, were obtained:

$\begin{array}{lrlr}\text { Triceps } & 15.35 \mathrm{~mm}, 4.0 \% & \text { Suprailiac } & 6.7 \mathrm{~mm}, \text { I } 1 \cdot 2 \% \\ \text { Biceps } & 7.90 \mathrm{~mm}, \mathbf{1} \cdot 9 \% & \text { Mid-thigh } & 34.32 \mathrm{~mm}, 3 \cdot 0 \% \\ \text { Scapula } & 10.52 \mathrm{~mm}, 4.0 \% & \text { Knee } & 12.92 \mathrm{~mm}, 4.7 \% \\ \text { Costal } & 10.00 \mathrm{~mm}, \quad 5.9 \% & \text { Total skinfolds } & 97.73 \mathrm{~mm}, 2.5 \%\end{array}$

Agreement between replicates was therefore reasonably good, the biceps and suprailiac sites involving a higher degree of inaccuracy than other sites. It may be reiterated that these results were obtained by a single experienced observer; another 
less-experienced observer obtained slightly different means with considerably higher coefficients of variation, on the same subjects. It is evident that skinfold measurements are relatively inaccurate and that a high degree of standardization is required to obtain reliable comparisons, even with one observer.

'Total skinfolds' (TSF), i.e. the sum of the values at the seven sites measured, is frequently used in presenting our results. It is realized that this total is arbitrary, depending on the sites selected, and that it conceals important differences of behaviour at different sites. Attempts to devise a single 'skinfold index' which would be biologically more meaningful than the simple sum of skinfolds have not been fruitful. It will be shown below that TSF does in fact reflect changes in total maternal 'dry weight' (i.e. body-weight less body water) reasonably well. But the limitations of the total should be kept in mind when interpreting the findings.

\section{RESULTS}

Table I gives some descriptive statistics for the whole series of patients and for the group in whom estimates of total body water were made. For the latter, values are given for dry weight, which might be expected to relate more clearly to skinfold

Table I. Means and standard deviations of certain characteristics in (a) the whole series of eighty-four patients and (b) forty-eight patients, included in (a), in whom measurements of total body water were made

Characteristic:

Age (years)

Height $(\mathrm{cm})$

Weight ratio (\%)*

All patients

$(n=84)$

Body water series

$26 \cdot 1 \pm 3 \cdot 6$

$163 \cdot 1 \pm 6 \cdot 4$

$106 \cdot 7 \pm 11 \cdot 1$ $(n=48)$

Birth weight of baby $(\mathrm{g})$

$3405 \pm 414$

Body-weight (kg):

Io weeks

2o weeks

30 weeks

38 weeks

At discharge

At postnatal examination

$8 \cdot 8+8 \cdot 0$

$6 \mathrm{r} \cdot 8 \pm 8 \cdot 0$

$66 \cdot 5 \pm 8 \cdot 3$

$69 \cdot 7 \pm 8 \cdot 4$

$62 \cdot 7 \pm 8 \cdot 4$

$60 \cdot 8 \pm 8 \cdot 4$

$26 \cdot 2 \pm 3 \cdot 3$

$162 \cdot 5 \pm 5 \cdot 5$

$105^{\prime} \pm 10 \cdot 3$

$\overbrace{\text { Total weight }}^{33^{83} \pm 454}$ 'Dry weight'

Changes in body-weight (kg/week):

ro-20 weeks

20-30 weeks

$0.30 \pm 0.18$

$0.47 \pm 0.13$

$0.39 \pm 0.18$

$0.39 \pm 0.13$

Io-30 weeks

$0.39 \pm 0.12$

10 38 weeks

$3 \cdot 94 \pm 3 \cdot 26$

$57 \cdot 5 \pm 6 \cdot 6$

$60 \cdot 7 \pm 6 \cdot 1$

$65 \cdot 5 \pm 6 \cdot 4$

$68 \cdot 5 \pm 6 \cdot 3$

$6 x \cdot 1 \pm 6 \cdot 2$

$59 \cdot 3 \pm 6 \cdot 2$

$26 \cdot 3 \pm 5 \cdot 3$

$27 \cdot 6 \pm 4 \cdot 5$

$29 \cdot 6 \pm 4 \cdot 6$

$30.0 \pm 4.3$

-t

$28 \cdot 2 \pm 4 \cdot 5$

$0.33 \pm 0.18$

$0.48 \pm 0.13$

$0.36 \pm 0.19$

$0.13 \pm 0.26$

$0.4 \mathrm{r} \pm 0.13$

$0.19 \pm 0.19$

$0.06 \pm 0.31$

$0.40 \pm 0.12$

$0.17 \pm 0.14$

$0.13 \pm 0.13$

Net weight change $(\mathrm{kg})$ :

Discharge weight minus ro weeks weight (kg)

Postnatal weight minus ro weeks weight (kg)

$x \cdot 99 \pm 2 \cdot 70$

$3 \cdot 6 r \pm 3 \cdot 3^{8}$

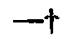

$\mathrm{r} \cdot 82 \pm 2 \cdot 67$

$r \cdot 83 \pm 3 \cdot 26$

* Weight ratio $=\frac{\text { body-weight at to weeks }}{\text { standard weight-for-height }}(\%)$. The standards used are those of Kemsley,

Billewicz \& Thomson, (1962).

$\dagger$ Total body water was not measured during the lying-in period. 
measurements than total body-weight. The patients in whom total body water was measured were slightly (not significantly) shorter and lighter than the series as a whole, but changes in body-weight during pregnancy were similar.

Table 2 gives the distributions of subjects by parity and by the presence or absence of clinical oedema during pregnancy, differentiating subjects in whom total body water was measured.

Table 2. Distribution of eighty-four patients by parity and presence or absence of oedema, differentiating those in whom total body water was measured

$\begin{array}{clccc}\text { Subjects } & \begin{array}{c}\text { Body water } \\ \text { measured }\end{array} & \begin{array}{c}\text { Body water } \\ \text { not measured }\end{array} & \text { All } \\ \text { Primiparae } & \text { Oedema present } & \text { I I } & \text { Io } & 2 \text { I } \\ & \text { Oedema absent } & \text { I4 } & 8 & 22 \\ \text { Multiparae } & \text { Oedema present } & 6 & 7 & \text { I3 } \\ & \text { Oedema absent } & \text { I7 } & \text { I I } & 28\end{array}$

Table 3. Statistics relating to the distribution of skinfolds at to weeks of pregnancy (eighty-four patients)

\begin{tabular}{|c|c|c|c|c|c|c|}
\hline \multirow[b]{2}{*}{ Site } & \multirow[b]{2}{*}{$\begin{array}{l}\text { Mean } \\
(\mathrm{mm})\end{array}$} & \multirow[b]{2}{*}{$\underset{(\mathrm{mm})}{\mathrm{SD}}$} & \multirow[b]{2}{*}{$\begin{array}{l}\text { Coefficient of } \\
\text { variation }(\%)\end{array}$} & \multicolumn{3}{|c|}{ Percentiles (mm) (approx.) } \\
\hline & & & & 25th & 5oth & $75^{\text {th }}$ \\
\hline Triceps & 15.7 & $5 \cdot 1$ & $32 \cdot 5$ & 12 & 15 & 19 \\
\hline Biceps & $7 \cdot 4$ & $3 \cdot \mathrm{I}$ & $4 \pi \cdot 9$ & 5 & 7 & 9 \\
\hline Scapula & II $\cdot 8$ & $4 \cdot 6$ & $39^{\circ} 0$ & 8 & II & 15 \\
\hline Costal & II $\cdot 4$ & $4 \cdot 7$ & $4 I \cdot 2$ & 8 & 10 & 14 \\
\hline Suprailiac & $7 \cdot 9$ & $3 \cdot \mathbf{I}$ & $39 \cdot 2$ & 6 & 7 & I0 \\
\hline Mid-thigh & $34 \cdot 8$ & 10.7 & 30.7 & 27 & 36 & 42 \\
\hline Knee & $11 \cdot 6$ & 3.8 & $32: 8$ & 8 & 12 & I4 \\
\hline Sum of values at all & 100.7 & 30.2 & $30 \cdot 0$ & 77 & 100 & 130 \\
\hline
\end{tabular}

Skinfolds at 1o weeks of gestation

As others have found, the distributions of skinfold thicknesses are positively skewed. The use of logarithmic transformations (Edwards et al. 1955) was considered and rejected, because: $(a) \log$ transformations did not fully normalize the distributions, and (b) the distribution curves changed shape during the course of pregnancy and the puerperium, so that no single form of transformation would be equally appropriate throughout. In the analyses which follow, untransformed values are used.

Table 3 gives some general information about the distributions of skinfold measurements at ro weeks of pregnancy. From this table, the average contribution of the skinfolds at various sites to TSF can be inferred.

Table 4 gives the coefficients of correlation between skinfolds at different sites, TSF, height, body-weight and weight ratio, i.e. body-weight relative to standard weight-for-height. There were high correlations between all pairs of sites, and the highest correlations were those with TSF. There was little, if any correlation between skinfolds and stature, fairly high correlations with body-weight, and still higher correlations with weight ratio. The coefficients did not differ much from site to site, i.e. no clear 'preferences' emerged. Table 5 gives correlation coefficients relating 
skinfolds to certain maternal characteristics in the forty-eight patients in whom total body water was measured. Body fat was estimated by means of the formula:

Fat $=$ body-weight $-\mathrm{I} \cdot 39 \times$ total body water.

This formula is derived by assuming that the lean body mass contains $72 \%$ water (Keys \& Brožek, I953). It is therefore not strictly applicable during pregnancy when the hydration of the lean body mass may change, but it should give results that are not excessively misleading in early pregnancy.

\section{Table 4. Coefficients of correlation between skinfold measurements at different sites, and between skinfolds and certain maternal characteristics}

(All measurements at ro weeks of pregnancy)

\begin{tabular}{|c|c|c|c|c|c|c|c|c|c|c|c|}
\hline Site... & $\mathbf{I}$ & 2 & 3 & 4 & 5 & 6 & 7 & 8 & Height & Weight & $\begin{array}{l}\text { Weight* } \\
\text { ratio }\end{array}$ \\
\hline I. Triceps & $\mathbf{I}$ & 0.87 & 0.71 & 0.68 & 0.67 & 0.83 & 0.63 & 0.92 & 0.29 & 0.69 & 0.72 \\
\hline 2. Biceps & - & I & 0.76 & 0.70 & 0.63 & 0.77 & 0.61 & 0.88 & 0.09 & 0.58 & 0.70 \\
\hline 3. Scapula & - & - & I & 0.70 & 0.71 & 0.68 & 0.60 & 0.84 & -0.10 & 0.41 & $0.6 \mathrm{I}$ \\
\hline 4. Costal & - & - & - & I & 0.76 & 0.61 & 0.52 & 0.80 & -0.05 & 0.42 & $0.5^{8}$ \\
\hline 5. Suprailiac & - & - & - & - & I & 0.66 & 0.50 & 0.80 & 0.04 & 0.50 & 0.62 \\
\hline 6. Mid-thigh & 一 & - & 一 & - & - & I & 0.64 & 0.92 & $0.1 \mathrm{I}$ & 0.59 & 0.69 \\
\hline 7. Knee & 一 & - & - & - & - & - & I & 0.75 & 0.03 & 0.52 & 0.66 \\
\hline 8. TSF & $\ldots$ & 一 & - & - & - & - & - & I & 0.08 & 0.63 & 0.77 \\
\hline
\end{tabular}

Table 5. Coefficients of correlation between skinfolds and certain characteristics of patients in whom total body water was measured

(Results for 10 weeks of gestation)

\begin{tabular}{lccccc}
\multicolumn{1}{c}{ Site } & $\begin{array}{c}\text { Body- } \\
\text { weight* }\end{array}$ & $\begin{array}{c}\text { Dry } \\
\text { weight* }\end{array}$ & $\begin{array}{c}\text { Weight } \\
\text { ratio }\end{array}$ & $\begin{array}{c}\text { Fat } \\
\text { body-weight } \%\end{array}$ & $\frac{\text { Fat }}{\text { dry-weight } \%}$ \\
Triceps & 0.64 & 0.75 & 0.64 & 0.74 & 0.72 \\
Biceps & 0.73 & $0.8 \mathrm{I}$ & 0.72 & 0.76 & 0.72 \\
Scapula & 0.63 & 0.69 & 6.63 & 0.66 & 0.63 \\
Costal & 0.66 & 0.64 & 0.64 & 0.56 & 0.55 \\
Suprailiac & 0.71 & 0.61 & 0.58 & 0.59 & 0.58 \\
Mid-thigh & 0.67 & 0.80 & 0.65 & 0.83 & 0.82 \\
Knee & 0.63 & 0.67 & 0.62 & 0.60 & 0.58 \\
TSF & 0.76 & 0.85 & 0.75 & 0.83 & 0.8 I
\end{tabular}

TSF, sum of values at all sites.

* Influence of height eliminated by partial correlation.

The values in Table $\mathbf{5}$ show no great differences between the various skinfolds when related to the five other variables. It is perhaps disappointing that fat, expressed as a percentage of body-weight or of dry weight, did not correlate with skinfolds better than the other variables. This may be due to inaccuracy in the estimation of fat with the formula used. Nevertheless, when the forty-eight subjects were ranked according to the estimates of fat as a percentage of body-weight, according to weight ratio and according to the value of TSF, the following rank correlations were obtained:

$$
\begin{array}{ll}
\% \text { fat } \times \text { weight ratio } & 0.63 \\
\% \text { fat } \times \text { TSF } & 0.84
\end{array}
$$


This indicates that ranking in terms of TSF agrees better with that obtained from estimates of the proportion of body-weight due to fat, than does ranking obtained from weight ratios. This is as it should be because skinfolds should reflect the amount of body fat better than weight ratios, which depend in large measure upon components of body-weight other than fat.

\section{Changes in skinfolds during pregnancy and the puerperium}

Table 6 gives the mean skinfold measurements and their standard deviations at various stages of pregnancy and the puerperium. Fig. I shows the absolute changes in the individual sites. At all sites except the knee, there was an appreciable, sometimes a considerable, increase between Io and 30 weeks of pregnancy. It can readily be shown, by calculating from the values in Table 6 , that the increases in the pregnant

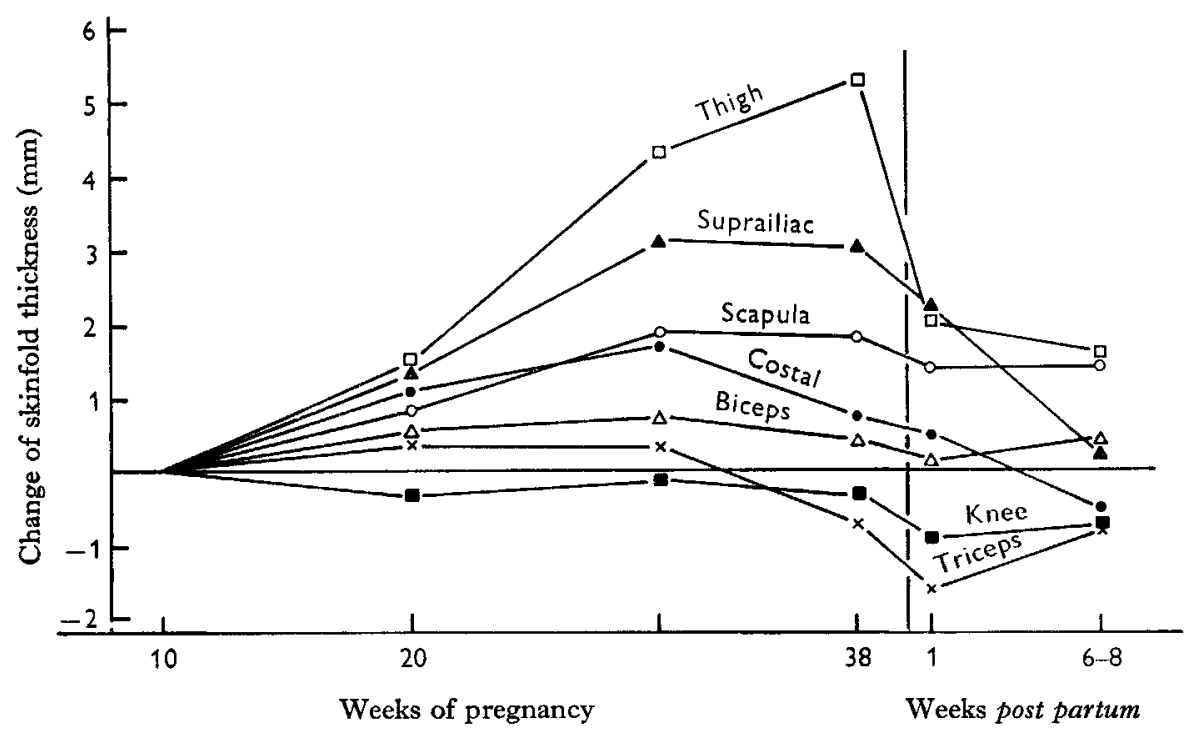

Fig. I. Absolute changes in skinfold thicknesses during and after pregnancy.

women were not proportional to the original thickness of the skinfold at each site. Fig. 2 shows that the proportional increase was by far the greatest at the suprailiac site, there were moderate proportional increases at scapula, costal, mid-thigh and biceps, but little or no change at triceps and knee. As a broad generalization, it appears that changes between 10 and 30 weeks are greatest, absolutely as well as proportionately, at 'central' sites, and least at 'peripheral' sites.

The patterns from 30 to 38 weeks of pregnancy were variable. The mid-thigh skinfold continued to increase, and costal and triceps skinfolds decreased. Other sites showed little change.

There was an overall decrease of surprisingly large dimensions from the $3^{8 \text { th }}$ week of pregnancy to the end of the first post-partum week. As Figs. 1 and 2 show, all sites decreased during this period. 
Vol. 21

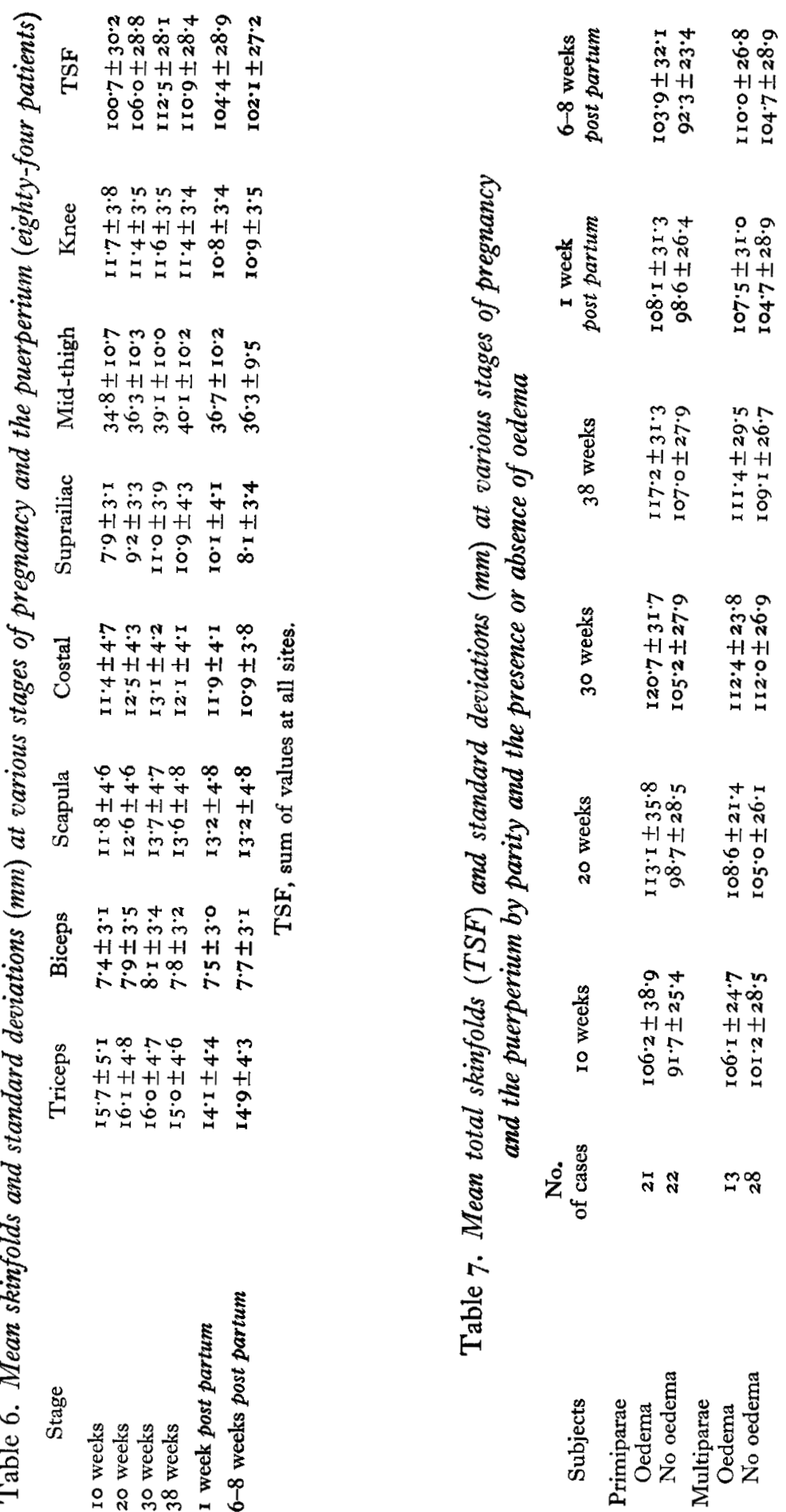


An attempt was made to define more closely the timing of the reduction of TSF between the $3^{8 \text { th }}$ week of pregnancy and about I week post partum. In thirteen primiparae and nine multiparae whose skinfolds were measured daily from the 2nd to the 6th day post partum, there was an average reduction in TSF of $\mathrm{I}^{\circ} 4 \mathrm{~mm}$, which was not significant. There was no evidence that the early puerperal change (if any) was influenced by the presence or absence of oedema during pregnancy, or by the administration of stilboestrol to suppress lactation.

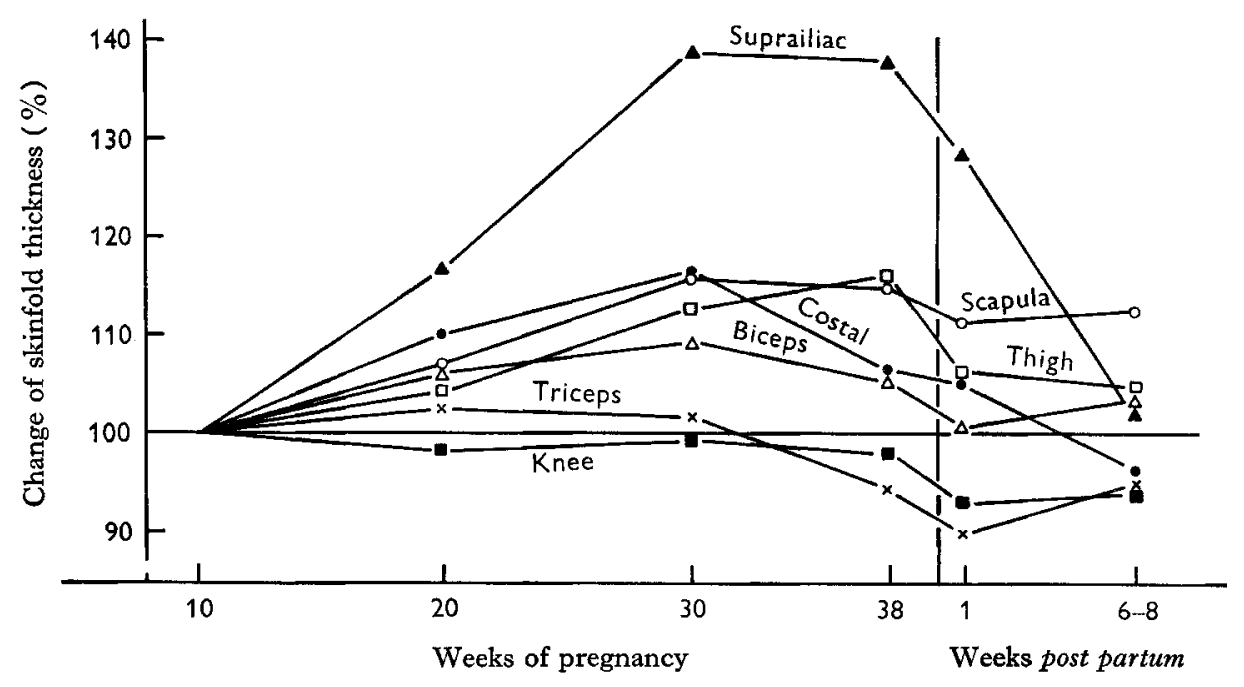

Fig. 2. Proportional changes in skinfold thicknesses during and after pregnancy.

In several subjects, skinfolds were measured after the 38 th week of pregnancy, and the following figures show the average decrease in TSF from the last measurement made during pregnancy to the 2nd post-partum day:

$\begin{array}{ccc}\begin{array}{c}\text { Final measurement } \\ \text { in pregnancy } \\ \text { made in }\end{array} & \begin{array}{c}\text { No. of } \\ \text { subjects }\end{array} & \begin{array}{c}\text { Average change } \\ \text { of TSF to } \\ \text { 2nd day } \\ \text { post partum }(\mathrm{mm})\end{array} \\ \text { 38th week } & 3 & -7.0 \\ \text { 39th week } & 7 & -4 \cdot 9 \\ \text { 40th week } & 2 & -9 \cdot 1 \\ \text { 41st week } & 3 & -11 \cdot 5\end{array}$

These figures suggest that the loss occurs in the few days immediately before or immediately after delivery. If the figures are arranged according to the number of days between the final measurement in pregnancy and the 2nd post-partum day, we get the following averages:

$\begin{array}{rcc}\text { Days } & \text { Subjects } & \mathrm{mm} \\ 2-3 & 6 & -6 \cdot 5 \\ 6-11 & 5 & -7 \cdot 0 \\ \mathbf{1 2 - 1 5} & 4 & -8 \cdot 6\end{array}$


This strongly suggests that the greater part of the loss in skinfold thicknesses between the last measurement in later pregnancy and the 6th post-partum day occurs rather abruptly immediately after delivery.

From the end of the Ist post-partum week to the postnatal examination at 6-8 weeks, the patterns were again variable. Suprailiac and costal decreased appreciably, triceps increased, and other sites showed little change.

By 6-8 weeks post partum the mean value of TSF had almost, but not quite, returned to the mean value at 10 weeks of gestation.

\section{Effect of parity and oedema on skinfolds}

The distribution of subjects by parity and presence or absence of oedema during pregnancy has been shown in Table 2. Table 7 shows the changes in TSF in each of the four subgroups. In both parity groups, the initial TSF thickness (at ro weeks) was greater in patients who subsequently showed oedema than in those who did not, suggesting that oedema tends to occur more commonly among relatively obese patients. As might be expected, the initial TSF thickness was slightly greater among multiparae than among primiparae (but not among those in each group who developed oedema).

Increase of TSF during pregnancy was greater, on average, among primiparae than among multiparae. Within each group, the pattern of change was not affected in any consistent manner by oedema. In particular, oedema was not associated with greater increases during the period $30-38$ weeks of pregnancy, nor with greater decreases during the period 38 weeks to the end of the lying-in period. Similar results can be demonstrated for individual skinfold sites.

Changes in total body-weight were slightly less among multiparae than among primiparae, and this difference corresponded to differences in skinfold change. On the other hand, in each parity group, the changes in dry weight were almost identical, whether or not oedema occurred. It is interesting that, among multiparae, changes in TSF appeared to be less in those who showed oedema than in those who did not. But since the same pattern did not appear in primiparae, it is difficult to draw any firm conclusions.

\section{Effect of initial weight ratio and initial skinfold thickness on changes in skinfolds during pregnancy}

Relatively obese women (i.e. those with high ratios of observed to standard weightfor-height at ro weeks of pregnancy) had smaller increases in skinfolds during pregnancy than relatively thin women. This is shown by negative correlation coefficients relating changes in TSF between various intervals, and the weight-for-height ratios at Io weeks (Table 8). As would be expected, increments in TSF during pregnancy were greatest in those subjects with smallest initial skinfolds (Table 9). 
Table 8. Correlation coefficients relating change in sum of skinfolds (TSF) between the intervals indicated and weight-for-height ratio at to weeks of pregnancy (eighty-four subjects)

\begin{tabular}{lc}
\multicolumn{1}{c}{ Interval } & $\begin{array}{c}\text { Correlation } \\
\text { coefficient }\end{array}$ \\
I0-20 weeks & -0.23 \\
20-30 weeks & -0.18 \\
30-38 weeks & -0.19 \\
I0-30 weeks & -0.28 \\
I0-38 weeks & -0.33 \\
I0 weeks to discharge from hospital & -0.27 \\
IO weeks to postnatal examination & -0.26
\end{tabular}

Table 9. Increments in sum of skinfolds $(T S F)$ by size of TSF at Io weeks of pregnancy

TSF at
Io weeks
(mm)
$<70$
$70-$
$90-$
$110-$
$130+$

\begin{tabular}{|c|c|}
\hline $\begin{array}{l}\text { No. of } \\
\text { subjects }\end{array}$ & $\begin{array}{c}\text { Mean } \\
\text { increment } \\
\text { in TSF, } \\
\text { 10-38 weeks }(\mathrm{mm})\end{array}$ \\
\hline I 5 & $+22 \cdot 0$ \\
\hline 17 & +17.5 \\
\hline 21 & $+\mathrm{YI}^{-4}$ \\
\hline 16 & +3.7 \\
\hline I 5 & -3.9 \\
\hline
\end{tabular}

Relationship between changes in body-weight and changes in TSF

The following values give the proportional increases in total body-weight, dry body-weight and TSF in the forty-eight subjects in whom measurements of total body water were made; measurements at Io weeks of pregnancy are taken as I00:

\begin{tabular}{|c|c|c|c|}
\hline Weeks of pregnancy & Total weight & Dry weight & $\mathrm{TSF}$ \\
\hline 10 & $100 \cdot 0$ & $100 \cdot 0$ & 100.0 \\
\hline 20 & 1057 & 105.2 & $107^{\circ} 0$ \\
\hline 30 & I I $3 \cdot 9$ & I.12:5 & I $14 \cdot 3$ \\
\hline $3^{8}$ & II 9 I & $\mathrm{II} 4^{\circ} 2$ & I I I 5 \\
\hline 6-8 post partum & 103.2 & $107 \cdot 2$ & $101 \cdot 3$ \\
\hline
\end{tabular}

TSF increased in roughly the same manner as both total weight and dry weight up to 30 weeks of pregnancy. Total weight continued to increase rapidly from 30 to 38 weeks, whereas dry weight increased only slightly and TSF showed a small decrease. A possible explanation might be that the small terminal increase in dry weight is largely attributable to the growth of the product of conception, which more than compensates for a small decrease in maternal fat reserves. On the other hand, it is difficult to account for the fact that maternal dry weight 6-8 weeks post partum was still considerably above dry weight at to weeks of pregnancy, whereas TSF was then nearly back to its initial thickness.

\section{The prediction of dry weight from skinfolds}

Since TSF is fairly closely related to dry weight, it seemed worth inquiring whether (a) dry weight can be predicted more precisely by some different method of 'com- 
bining' individual skinfold measurements; $(b)$ whether the number of skinfold sites can be restricted; and $(c)$ which are the 'best' sites to use during pregnancy for the purpose of estimating dry weight.

The best and most consistent predictions were obtained at each step of gestation from regressions based on maternal height and skinfold thicknesses at biceps, suprailiac, mid-thigh and knee. Table ro summarizes the findings. It is clear that estimates of dry weight from height and skinfolds at $3^{0-38}$ weeks are subject to greater errors than at other times. This is, of course, not unexpected, because the contribution of the product of conception to dry weight is greatest at those times, and because skinfold measurements at the suprailiac and mid-thigh sites are sometimes rather difficult to measure precisely at those stages.

Table 10. Residual mean squares and multiple correlation coefficients for regressions of dry weight on maternal height and skinfold measurements at biceps, suprailiac, mid-thigh and knee, at various stages of gestation

$\begin{array}{ccc}\text { Stage of gestation (weeks) } & \begin{array}{c}\text { Residual } \\ \text { mean } \\ \text { square } \\ (42 \mathrm{df})\end{array} & \begin{array}{c}\text { Multiple } \\ \text { regression } \\ \text { coefficient }\end{array} \\ \text { Io } & 6.36 & 0.88 \\ 20 & 5.66 & 0.85 \\ 3 \circ & 7.57 & 0.80 \\ 3^{8} & 8.85 & 0.72 \\ \text { 6-8 weeks post partum } & 4.39 & 0.88 \\ \text { Differences, postnatal minus ro weeks } & 3.39 & 0.82\end{array}$

Further calculations showed that no single equation based on the variables so far examined would serve at all stages of gestation, so gestation was introduced as an additional variable, in the following equation:

$$
\begin{aligned}
\text { dry weight }= & 0.3496 \text { height }+0.6729+0.21 \text { I I suprailiac } \\
& +0.0868 \text { mid-thigh }+0.2219 \text { knee }-0.3120 \text { gestation } \\
& +0.0168 \text { gestation }{ }^{2}-0.0002 \text { gestation }{ }^{3}-40 \cdot 1869,
\end{aligned}
$$

where dry weight is in $\mathrm{kg}$, height in $\mathrm{cm}$, skinfolds in $\mathrm{mm}$, and gestation in $n^{\text {th }}$ weeks.

This equation, when applied to the whole group of subjects in whom total body water had been measured, estimated mean dry weights at various stages of pregnancy to within $0.05 \mathrm{~kg}$ of the measured means, and the standard deviations of differences between estimated and measured dry weights were $2 \cdot 6,2 \cdot 3,2 \cdot 7,2 \cdot 9$ and $2 \cdot \mathrm{I} \mathrm{kg}$ at Io, $20,3^{\circ}, 3^{8}$ weeks of gestation and 6-8 weeks post partum respectively.

\section{DISCUSSION}

During early pregnancy, skinfold thicknesses at seven sites, separately or together, showed good correlations with total body-weight, 'dry weight', and with ratio of observed to standard weight-for-height. They were also correlated with calculated estimates of total body fat as a proportion of total body weight and dry weight.

Skinfold thicknesses at most sites, especially around the trunk and upper legs, 
increased fairly rapidly from to to 30 weeks of pregnancy, and thereafter remained constant or fell slightly. These patterns correspond in a general way with the pattern of maternal fat deposition during pregnancy, which has been inferred from measurements of body-weight and body composition by Thomson \& Hytten (I96I) and Hytten \& Leitch (1964). Furthermore, there is evidence that the skinfolds of women who are initially overweight tend to increase less than those of women who are initially underweight. Increases in skinfolds appeared to be slightly less among multiparae than among primiparae. 'The occurrence of oedema in pregnancy was not associated with any consistent alteration in the pattern of skinfold change.

Though the patterns of skinfold change during pregnancy were thus broadly consistent with what is known of changes in maternal body composition, continuation of the measurements after delivery revealed some unexpected features. In the first place, TSF and skinfolds at most individual sites showed a sharp reduction between 38 weeks of pregnancy and the end of the lying-in period, about a week post partum; as already explained, this loss of skinfold thickness appeared to occur rather abruptly about the time of parturition. It cannot plausibly be explained by a reduction of maternal subcutaneous fat. Nor can it be explained as due to the elimination of superficial oedema: the amount of skinfold 'lost' was almost the same in women who had had oedema, as in those who had not.

The second unexpected feature is that at the time of the postnatal examination, 6-8 weeks post partum, most skinfold sites had reverted nearly to their size at to weeks of pregnancy. The value of TSF was then only $1 \cdot 3 \%$ greater, whereas total bodyweight was greater by $3 \%$ and dry weight by $7 \%$, presumably largely owing to increase of body fat (see p. 448). In the absence of any means of relating these measurements to change in total body fat, we can only speculate about possible reasons for the apparent discrepancy. One hypothesis would be that skinfolds increase during the first ro weeks of pregnancy from some cause that is not increase of subcutaneous fat, and that this cause disappears after parturition. The 'corrected' increase in TSF (ex hypothesi that due to increase of subcutaneous fat) would then show improved correspondence with change in dry weight during and after pregnancy. But there is nothing to support such an explanation; indeed in fifteen subjects for whom we have skinfold measurements before conception and during the first weeks of pregnancy, there is no evidence of any increase in skinfold thickness during this early phase. Another possibility, which would be difficult to test, is that the disproportionately large increase in dry weight is largely due to the accumulation of fat in the internal depots, rather than subcutaneously. Again, it should be borne in mind that the skinfolds which can be measured in pregnant women may not reflect very accurately the overall increase in total subcutaneous fat.

Despite these anomalous features, the measurement of skinfolds does confirm what has been inferred from indirect evidence (Hytten \& Leitch, 1964), and what is clear to pregnant women themselves: that pregnancy is accompanied by considerable storage of body fat. But there seems to be an additional factor causing increase of skinfolds during pregnancy, which disappears rather abruptly at the time of parturition. The nature of this additional factor is unknown; it does not appear to be cutaneous oedema. 


\section{REFERENCES}

Edwards, D. A. W., Hammond, W. H., Healy, M. J. R., Tanner, J. M. \& Whitehouse, R. H. (I955). Br.F. Nutr. 9, 133 .

Hytten, F. E. \& Leitch, I. (1964). The Physiology of Human Pregnancy. Oxford: Blackwell Scientific Publications.

Hytten, F. E., Thomson, A. M. \& Taggart, N. (1966). F. Obstet. Gynaec. Br. Commonw. 73, 553.

Kemsley, W. F. F., Billewicz, W. Z. \& Thomson, A. M. (I962). Br. F. prev. soc. Med. 16, I89.

Keys, A. \& Brožek, J. (1953). Physiol. Rev. 33, 245.

Thomson, A. M. \& Hytten, F. E. (1961). Proc, Nutr. Soc. 20, 76. 